\title{
O Pequeno Grupo "Oficina de Capoeira" no contexto da Reforma Psiquiátrica '
}

\section{The Small "Capoeira Workshop" Group in the Context of Psychiatric Reform}

\author{
Míriam Cristiane Alves \\ Educadora Física Especialista em Saúde Mental Coletiva, Mestre \\ em Psicologia Social / PUCRS. \\ E-mail: miriamalvesळcpovo.net \\ Nedio Antônio Seminotti \\ Professor Pesquisador do Programa de Pós-Graduação da Facul- \\ dade de Psicologia PUCRS, Doutor pela Universidad Autónoma \\ de Madrid. \\ E-mail: nediosळpucrs.br \\ 10 presente artigo é resultado da Dissertação de Mestrado \\ intitulada "Produção e Organização do Sistema Pequeno Grupo \\ 'Oficina de Capoeira': um estudo no contexto da reforma psi- \\ quiátrica", PUCRS. Órgão Financiador: CAPES.
}

\section{Resumo}

A Oficina de Capoeira nasceu a partir da necessidade de inter-relação entre o Hospital Psiquiátrico São Pedro e a Vila São Pedro, haja vista a construção dos Serviços Residenciais Terapêuticos em parte da área territorial da vila. Composta de moradores da vila e usuários do hospital, esta oficina foi escolhida como objeto de estudo devido a sua singularidade, diversidade e contextualização na reforma psiquiátrica. Este estudo objetiva esclarecer como se produz e se organiza o sistema Pequeno Grupo Oficina de Capoeira, utilizando como principal referencial o Paradigma da Complexidade de Edgar Morin. As informações foram registradas a partir de observações e anotações em diário de campo. Participaram da pesquisa os sujeitos que constituíram a Oficina de Capoeira. Esta proposta nos sugere outras possibilidades de intervenção em pequenos grupos no contexto da reforma psiquiátrica. Todavia, precisamos viver a heterogeneidade e a incerteza do sistema como possibilidade de produção de sujeitos criativos.

Palavras-chave: Capoeira; Pequeno Grupo; Sistema vivo; Organização; Complexidade; Reforma psiquiátrica. 


\section{Abstract}

The Capoeira workshop was formed from the need to strengthen the relationship between the Hospital Psiquiátrico São Pedro and the Vila São Pedro neighborhood, considering the construction of the Residential Therapeutic Services unit in the neighborhood. Composed of local residents and users of the hospital, the workshop was chosen as an object of study due to its uniqueness, its diversity and for the way it places psychiatric reform in context. The study aimed to understand how the small Capoeira Workshop group is produced and organized. The principal theoretical reference for the study was the Complexity Paradigm of Edgar Morin. The data was collected from observations and notations in a field notebook. Study participants included the subjects who composed the Capoeira Workshop. This created other possibilities for intervention in small groups in the context of psychiatric reform. Nevertheless, we need to experience the heterogeneity and the uncertainty of the system as a possibility for the production of creative subjects. Keywords: Capoeira; Small Group; Living System; Organization; Complexity; Psychiatric Reform.

\section{Introdução}

O tema do presente estudo emerge do encontro da pesquisadora com sua prática profissional no Hospital São Pedro ${ }^{2}$ e na Vila São Pedro 3 , bem como de sua formação em Educação Física e em Saúde Mental Coletiva. Também é fruto de sua caminhada junto ao movimento de Reforma Psiquiátrica. Utilizou-se como referencial o Paradigma da Complexidade desenvolvido por Morin, buscando produzir um outro olhar para o pequeno grupo Oficina de Capoeira tomado aqui como sistema pequeno grupo.

A discussão sobre o pequeno grupo como um sistema vivo (Alves e Seminotti, 2005) é construída na interlocução entre os campos do saber da Sociologia, da Psicologia Social e da Psicologia dos Grupos. Conforme os autores, a discussão ocupa-se dos processos de organização e desorganização, de subjetivação e sujeição, produzidos na inter-relação entre diferentes sujeitos e sistemas que constitui a rede de sistemas interdependentes onde o objeto/sistema ${ }^{3}$ de estudo está contextualizado.

A Oficina de Capoeira foi escolhida como objeto/ sistema de estudo por ser um pequeno grupo aberto e heterogêneo; por estar contextualizado junto ao movimento de Reforma Psiquiátrica; e por propor a interação entre o Hospital São Pedro e a Vila São Pedro por meio da capoeira. O Pequeno grupo Oficina de Capoeira torna-se, portanto, um fecundo campo de investigação para a produção de conhecimento, oferecendo grandes possibilidades de transversalizações, considerando a complexidade de relações que nele se produzem e se evidenciam.

Na prática, e pela prática, a reforma psiquiátrica tem ganhado novos adeptos e avançado na desconstrução do aparato manicomial, na ampliação de direitos civis, políticos e sociais dos sujeitos portadores de sofrimento psíquico, no controle social, na consolidação da democracia, entre outros (Kinoshita, 200o; Rosa, 1998). A reforma tem construído importantes ações e intervenções, que vêm consolidando a produção de uma clínica ampliada em saúde mental. Estu-

1 O Hospital São Pedro é o único hospital psiquiátrico público do Estado do Rio Grande do Sul.

2 A partir de 1974, ocorreram as primeiras invasões e ocupações irregulares em parte da área pertencente ao Hospital São Pedro que, atualmente, corresponde à Vila São Pedro.

30 termo objeto \sistema de estudo está articulado à noção de que não existe uma realidade independente de um observador (Morin, $2002 \mathrm{a}, 2002 \mathrm{~b}, 2003)$. 
diosos da área apontam para a perspectiva de um novo paradigma clínico em saúde mental (Baremblitt, 1997; Deleuze, 1997; Goldberg, 1996; Guattari, 1992; Macedo e Maron, 1997), uma "clínica da cidadania" (Lancetti, 1997). Exige-se cada vez mais a produção de novos modos de cuidado da saúde mental (Amarante, 1994), de novos dispositivos de atenção, que operem na produção de subjetividade e provoquem novos modos de existência (Ziegelmann, 2002), que se tornem construtores de sujeitos de transformação (Wetzel e Almeida, 2001) e que atuem na desconstrução de estigmas acerca da saúde/doença mental no âmbito da sociedade. Assim, são desenvolvidas ações e intervenções que transcendem a oferta exclusivamente medicalizante, pautadas em princípios éticos, que envolvem a construção de direitos e de cidadania, que enfatizam a reabilitação psicossocial, e que incluem neste processo a gestão da vida cotidiana das pessoas, a ampliação da rede social, o aumento da autonomia (Cambraia, 1999; Macedo e Maron, 1997; Tenório, 2002; Villas-Bôas Valero, 2001), a produção de autopoiésis (Lancetti, 1997; Ziegelmann, 2002).

Ziegelmann (2002) aborda a possibilidade de uma nova clínica de saúde mental na atualidade, por meio do trabalho em grupos, (Villas-Bôas Valero, 2001), de uma oficina de artes plásticas e (Alves e Malavolta, 2002), de uma oficina de capoeira, porém, a produção teórica sobre as práticas que envolvem os pequenos grupos ainda encontra-se incipiente.

Consideramos que este seja o momento de tentar uma construção teórico-prática na articulação entre reforma psiquiátrica, pequenos grupos e complexidade. Um desafio que nos coloca ao lado do aleatório, do dialógico, da incompletude, da instabilidade, da incerteza, da ordem, da desordem, do caos. Nesta perspectiva, é que tomamos como referência o Paradigma da Complexidade, de Morin, (2002a), que em seu trabalho intitulado $O$ Método busca articular diversos campos do conhecimento e construir um campo de investigação sobre o conhecimento humano a partir da noção de complexidade - "conhecer o conhecer".

Neste sentido, a relevância desta pesquisa apresenta-se na construção de conhecimento em torno da articulação entre reforma psiquiátrica, pequenos grupos e complexidade; na construção de conhecimento em torno de outras possibilidades de intervenção em saúde mental; na contribuição com o desenvolvimento de uma saúde mental vista na perspectiva das relações; na possibilidade de resgate e construção de cidadania dos usuários das unidades de internação psiquiátrica do hospital e das crianças da comunidade da vila; e pela possibilidade de repercutir e produzir efeitos em outros sujeitos, espaços, pequenos grupos e grupos sociais.

O problema levantado para a construção do presente estudo refere-se à compreensão, à luz do paradigma da complexidade, da produção e da organização do sistema pequeno grupo Oficina de Capoeira contextualizado no movimento de reforma psiquiátrica. E o objetivo foi compreender como se produz e se organiza o sistema pequeno grupo Oficina de Capoeira.

\section{A Oficina de Capoeira}

A Oficina de Capoeira foi criada em março de 2002 e encerrou suas atividades em dezembro de 2004. Ela foi fundada pela necessidade de interação entre o Hospital São Pedro e a Vila São Pedro, haja vista a construção dos Serviços Residenciais Terapêuticos em parte da área territorial da vila, localizada nos fundos do hospital. Durante seu último ano de atividade, período em que foi realizada a investigação, participaram da Oficina de Capoeira: a) crianças moradoras da Vila São Pedro, com idades entre 5 e 12 anos; b) adultos portadores de sofrimento psíquico usuários das unidades de internação do Hospital São Pedro, com idades acima de 18 anos; c) um professor de Educação Física; d) a pesquisador, totalizando, no máximo, 25 pessoas por encontro.

As crianças da Oficina de Capoeira mantinham-se, por um período de tempo maior, no pequeno grupo. A escolha entre participar ou não estava relacionada com o desejo das próprias crianças. Assim, a entrada no pequeno grupo ocorreu a partir da procura espontânea por parte das crianças e seus responsáveis. Quando existiam vagas, no máximo 13 para a comunidade da vila, o professor de Educação Física e $\backslash$ ou a pesquisadora solicitavam que as crianças retornassem com um de seus responsáveis e, em caso de impossibilidade, eles se dirigiam até a moradia da criança. Neste encontro, conversava-se sobre os objetivos da oficina, a participação de moradores e usuários do hospital, os horários e dias de sua realização e a possibilidade de passeios em outros espaços da cidade. Para que a criança pudesse participar, o responsável assinava um documento autorizando. 
Os usuários das unidades de internação psiquiátrica do hospital possuíam um tempo pré-determinado para a entrada e para a saída da Oficina de Capoeira, que estava diretamente relacionado com o tempo instituído para o tratamento nestas unidades - em média 45 dias. Tendo em vista que nos primeiros dias de internação as pessoas ainda se encontravam na fase aguda da doença, a participação na oficina passava a acontecer somente quando elas estavam em avançado processo terapêutico, ou seja, a cerca de duas semanas da alta hospitalar. 0 convite era feito pelo professor de Educação Física, que esclarecia aos interessados a proposta de trabalho, a participação de crianças da comunidade da vila e a possibilidade de continuarem participando após a alta hospitalar.

O professor de Educação Física e a pesquisadora são considerados participantes da Oficina de Capoeira, pois, embora estivessem na posição de coordenadores do pequeno grupo, sempre estiveram comprometidos com os processos e os produtos construídos na relação entre partes e todo, entre sujeitos, pequeno grupo e contexto maior.

A Oficina de Capoeira constituía-se como um pequeno grupo aberto e heterogêneo, onde o jogo da capoeira era utilizado como principal técnica de intervenção, recurso expressivo e de organização do pequeno grupo. Além da capoeira, eram utilizados outros jogos e brincadeiras. Os encontros, coordenados pelo professor de Educação Física e pela pesquisadora, aconteciam uma vez por semana com duração de uma hora e trinta minutos. O ginásio "Gigantinho" do Serviço de Educação Física do Hospital São Pedro foi o principal espaço para a realização das atividades do grupo. porém também foram utilizados o gramado localizado em frente à fachada principal do hospital, a área central da vila e o espaço que corresponde aos Serviços Residenciais Terapêuticos.

A capoeira desenvolvida na oficina não era identificada por estilo - regional, angola ou contemporânea -, grupo ou qualquer outro tipo de classificação. Ela reunia diferentes modos de ser e fazer capoeira, expressos por seus participantes que, muitas vezes, já possuíam algum tipo de experiência e conhecimento sobre a prática. A capoeira desta oficina foi, portanto, construída na interação entre seus participantes, na multiplicidade e na diversidade de saberes expressos por seus participantes.

\section{O Sistema Pequeno Grupo}

A ambição da complexidade é prestar contas das articulações despedaçadas pelos cortes entre disciplinas, entre categorias cognitivas e entre tipos de conhecimento (Morin, 2002a, 2002b). 0 pensamento complexo (Morin, 1996, 2002a, 2002b, 2003) traz a idéia de complexificação das relações; a um só tempo, separa e associa, reduz e complexifica, trazendo a relação de convívio e inseparabilidade dos antagônicos, dos concorrentes, dos contrários. Esse pensamento se constrói a partir de sete princípios: sistêmico, dialógico, hologrâmico, do circuito retroativo, do circuito recursivo, da auto-organização e da reitrodução do observador na observação (Morin, 1996, 2002a, 2002b, 2003).

Segundo Morin (2002a, 2002b), o sistema é unidade e multiplicidade a um só tempo, ou seja, unidade múltipla. Nas palavras deste autor, o sistema é o que "exprime a unidade complexa e o caráter fenomenal do todo, assim como o complexo das relações entre o todo e as partes" (2002b, p. 265). 0 importante não é o número de elementos ou de partes de um conjunto, mas as inter-relações nele estabelecidas que, por sua vez, constituirão uma unidade global. Para Morin (2002a, 2002b), estas duas características da definição de sistema, ou seja, a inter-relação e a unidade global precisam ser ligadas pela idéia de organização. Assim que adquirem um caráter regular, as inter-relações das partes, dos elementos, dos acontecimentos tornam-se organizacionais.

A noção de pequeno grupo apresentada neste estudo acompanha a conceituação dos teóricos grupalistas, que tomam como característico o fato de propiciar aos sujeitos que compõem o grupo a possibilidade de todos se verem e se ouvirem simultaneamente, conhecerem-se e reconhecerem-se em suas singularidades e diversidades devido ao número reduzido de participantes (Seminotti, 200o).

Tomar o pequeno grupo como um sistema vivo (Alves e Seminotti, 2005) implica em considerar que os sistemas sociais envolvem não apenas seres humanos vivos como também a linguagem, a consciência e a cultura (Capra, 2002). Nesse sentido, conforme o autor, torna-se evidente que sejam sistemas cognitivos e, desse modo, "parece estranho pensar que não sejam vivos" (2002, p. 94).

Nesta perspectiva, compreendemos o sistema pe- 
queno grupo como um sistema vivo formado por sujeitos humanos possuidores de linguagem, cultura e consciência. A estas atividades humanas, acrescentamos a comunicação e a história de vida. Dessa forma, são muitos os elos que se interconectam para a produção e a organização do sistema pequeno grupo. Além dos já citados, não podemos deixar de considerar os processos de inter-relação, de organização e desorganização, de subjetivação e sujeição, de caos e ordem entre partes e todo, entre sujeitos, pequeno grupo e sistema maior.

Conforme Morin (2002a, 2002b), um conjunto de interações constitui uma organização, que é o encadeamento de relações entre elementos, entre partes que produzem um sistema dotado de qualidades desconhecidas quanto aos elementos, às partes isoladamente. Morin (2002b) define a organização “como reorganização permanente de um sistema que tende a se desorganizar", "como reorganização permanente ..., isto é, não apenas organização, mas auto-reorganização" (2002b, p. 266). A organização cria ordem e desordem, ou seja, cria ordem criando seu próprio determinismo sistêmico que pode ser flexível, comportar suas zonas de aleatoriedade, ao mesmo tempo que cria desordem, produzindo degradação, degenerescência (Morin, 2002b). Organização é, portanto, ordem e desordem que se implicam mutuamente.

Tomando a noção de organização de Morin, apontamos para a emergência de organizadores grupais no sistema pequeno grupo, ou seja, elementos que potencializam e/ou inibem as interações, socializações e articulações entre diferentes sujeitos, entre estes, o pequeno grupo e o contexto maior (Alves e Seminotti, 2005). Seminotti (2004) trabalha com a idéia de organizadores formais e informais do pequeno grupo. Os primeiros são aqueles instituídos e levados ao grupo, como, por exemplo, o enquadre e a coordenação. Os segundos são aqueles que constroem a particularidade de cada pequeno grupo no aqui-e-agora, como a tarefa, os papéis, as lideranças, as comunicações. Os organizadores formais e informais contribuem com o processo de organização do sistema pequeno grupo.

Aidéia de recorrência organizacional proposta por Morin (2002b) é necessária para chegarmos a autoprodução e a auto-organização que permitem compreender os processos de subjetivação e sujeição, ou seja, a produção de modos de existência, de modos pelos quais os sujeitos se auto-experimentam, se autoproduzem nas inter-retroações entre partes e todo, entre sujeitos, pequeno grupo e sistema maior. Segundo Morin (1996, 2002b, 2003), os seres vivos, os humanos e as sociedades são auto-organizadores e não param de se autoproduzirem. Possuem uma autonomia que se fundamenta na dependência do meio ambiente e, nesse sentido, os sistemas vivos, humanos e sociais precisam ser concebidos como auto-ecoorganizadores.

$\mathrm{O}$ aparente antagonismo entre as noções de autonomia e de dependência nos remete a um sistema vivo aberto e fechado (Morin, 2002a, 2002b). Aberto, pois depende de informações do meio ambiente para continuar seu processo de amadurecimento, de crescimento, de desenvolvimento enquanto unidade e multiplicidade, e fechado, pois necessita preservar sua identidade, singularidade e originalidade, seu modo de viver.

Nesta perspectiva, a auto-organização que se produz no processo de interconexão e inter-relação com o meio ambiente através de um sistema vivo ao mesmo tempo aberto e fechado é, de fato, auto-ecoorganização (Morin, 1996, 2002b, 2003). O princípio de autoecoorganização é específico para os seres humanos e para as sociedades, haja vista que os seres humanos desenvolvem sua autonomia na dependência de sua cultura e as sociedades se desenvolvem na dependência de seu meio geológico (Morin, 2003).

A noção de sujeito de Morin (1996, 2003) parte de uma base biológica. Refere-se à relação de dependência do sujeito com seus meios biológico, social e cultural, visando a autonomia. É a noção de sujeito autoecoorganizado segundo a qual o sujeito se constrói a partir da noção de indivíduo, que, do ponto de vista biológico, é produto de um ciclo de reprodução. Todavia, ainda segundo este autor, para se chegar à noção de sujeito, esta organização biológica necessita de uma dimensão cognitiva/computacional, indispensável à vida.

O sujeito possui um caráter existencial, "porque é inseparável do indivíduo, que vive de maneira incerta, aleatória, e acha-se, do nascimento à morte, em um meio ambiente incerto, muitas vezes ameaçador e hostil" (Morin, 2003, p. 124). Ele "não é uma essência, não é uma substância, mas não é uma ilusão" (2003, p. 128). Conforme o autor, o sujeito é único e a individua- 
lidade não é apenas diferença e singularidade, mas também subjetividade.

A subjetividade, no presente estudo, é compreendida como um "vir-a-ser" aleatório, produzido em uma rede de sistemas interdependentes, na trama de interações entre espaços sociais, culturais e biológicos. Uma subjetividade que não é a raiz do ser, mas sim os modos de ser na auto-ecoorganização, na interação consigo, com o outro, com o sistema maior.

No pensamento complexo, conhecer o sistema vivo não implica em separá-lo do seu meio ambiente, mas contextualizá-lo nesse meio, considerando todos os acontecimentos e as informações que se relacionam a ele, numa relação de inseparabilidade. A contextualização não se refere simplesmente ao meio ambiente, mas às inter-relações entre os elementos envolvidos (Vasconcellos, 2003) e entre elementos e acontecimentos a um só tempo.

As noções de elemento e acontecimento estão intrinsecamente relacionadas: "todo elemento pode ser considerado acontecimento à medida que o consideramos situado na irreversibilidade temporal, uma manifestação ou atualização, isto é, em função de seu aparecimento e desaparecimento, como em função de sua singularidade" (Morin, 2002b, p. 251), ou seja, a noção de acontecimento implica na idéia de que uma situação pode ou não ocorrer, sendo o acontecimento, portanto, sempre uma contingência (Prigogine, 2003). Segundo esse autor, "o acontecimento mais insignificante pode mudar o curso da história” (Prigogine, 1996, p. 26).

Pensar o objeto/sistema de estudo contextualizado implica pensar em sistemas complexos, cujas múltiplas inter-retroações não se inscrevem numa causalidade linear, mas em relações causais retroativas e recursivas (Morin, 2002b, 2003).

\section{Método}

O referencial paradigmático de Ciência segundo o qual nos baseamos objetiva produzir recursivamente questionamentos, reflexões e intervenções para a construção desta investigação.

No trabalho $O$ Método, de Morin (2002b), a palavra método traz seu significado original: caminhada. E, nesse sentido, assumimos a proposição deste autor em construir um caminho enquanto avançamos por esta investigação. Conforme Morin (2003), o método deve ser construído durante a pesquisa, de modo que só possa emanar e se formular no momento em que o próprio método se transforma em um novo ponto de partida. 0 método ganha sentido, regulação, organização, transformando-se em um novo ponto de partida após inter-relações, recursões, retroações entre observador e observação.

Na perspectiva do pensamento complexo, buscamos construir um corpus de pesquisa com informações variadas, o que possibilitou a conexão estratégica entre elas. Foram incluídas todas as informações que, na relação entre observador e observação, expressaram as relações produzidas na Oficina de Capoeira e em sua rede de sistemas interdependentes. A construção de um corpus múltiplo, ou seja, um sistema múltiplo de informações, teve por objetivo dar visibilidade a esta rede de relações que extrapola as fronteiras da Oficina.

Participaram da pesquisa 12 crianças moradoras da Vila São Pedro; 39 adultos usuários das unidades de internação psiquiátrica do Hospital São Pedro; 1 professor de educação física; e 1 pesquisadora, totalizando 53 participantes, distribuídos ao longo de 14 encontros. Sendo que a cada encontro tínhamos no máximo 20 participantes.

No período entre os meses de maio e agosto de 2004, foram realizadas observações e anotações em diário de campo de 14 (quatorze) encontros da Oficina de Capoeira. Após a realização de uma primeira leitura sobre algumas das informações produzidas na inter-relação entre observador e observação, emergiu a necessidade de diálogo com os participantes da pesquisa. Ao mesmo tempo em que dialogávamos com as informações descritas no diário de campo, passamos a dialogar sobre elas com o professor de Educação Física da Oficina. Toda vez que esta interlocução acontecia, tínhamos a possibilidade de produzir novas informações, bem como validar e/ou invalidar o que já havia sido produzido.

Destes diálogos emergiu um grande eixo temático que denominamos "sistema pequeno grupo e sua rede de relações”. Esse eixo foi subdividido em quatro eixos: a rede de relações entre Comitê de Ética e a Oficina de Capoeira; a rede de relações entre a Vila São Pedro e a Oficina de Capoeira; as mudanças nas relações entre sujeitos e sistema pequeno grupo; a rede de re- 
lações entre os Serviços Residenciais Terapêuticos, a Vila São Pedro e a Oficina de Capoeira.

O estudo seguiu as normas do Conselho Nacional de Saúde (Brasil, 1996) e do Conselho Federal de Psicologia (Conselho Federal de Psicologia, 200o), que dispõem sobre a realização de pesquisa envolvendo seres humanos.

\section{A Oficina de Capoeira e a sua Rede de Relações}

O sistema pequeno grupo Oficina de Capoeira construiu uma rede de relações que extrapola suas fronteiras, haja vista a permeabilidade de um sistema que se manteve ao mesmo tempo aberto e fechado, ou seja, que se produziu com informações novas vindas do exterior, mas que, ao mesmo tempo, manteve-se fechado para preservar sua identidade, sua singularidade, a própria vida do sistema (Morin, 2002a, 2002b, 2003).

\section{A Rede de Relações entre Comitê de Ética e a oficina de Capoeira}

Uma das questões importantes a ser pensada e dialogada se refere à interação sistema pequeno grupo Oficina de Capoeira e organização Comitê de Ética, ao qual foi submetido o projeto desta dissertação. Segue fragmento de uma mensagem eletrônica redigida por um dos membros do Comitê.

\section{Estimado Nedio:}

(...) Um projeto de uma aluna tua sobre a utilização de capoeira em pacientes psiquiátricos gerou alguma polêmica no Comitê de Ética. Alguns membros ficaram preocupados com a instrumentalização dos pacientes em uma atividade física potencialmente utilizável em enfrentamento pessoal (...).

Afinal, o que se produziu na relação entre a Oficina e o Comitê?

Diríamos que, de um lado, o sistema pequeno grupo Oficina de Capoeira produziu um estranhamento e certa desordem na organização do Comitê de Ética, tendo em vista as discussões e os questionamentos que foram suscitados nas reuniões (conforme anuncia a mensagem acima transcrita), quando os membros do Comitê se depararam com a seguinte informação: "capoeira para usuários e usuárias das unidades de internação de um hospital psiquiátrico”. Houve estranhamento, porque, em um processo de subjetivação, os sujeitos que compõem o Comitê chegaram a cogitar a possibilidade de a capoeira ser utilizada como um instrumento de agressão aos trabalhadores do Hospital São Pedro. Para esse grupo de sujeitos, estamos falando em "loucos em crise",que pegam, agridem, são perigosos, não possui nenhum tipo de organização em sua desorganização. Essa “loucura”, que ainda é tomada como algo alheio a nossas vidas, a nossa sociedade, ou seja, pertencente a outrem, que está distante e que, nesse sentido, não está interligado, articulado, socializado, integrado a essa grande rede de sistemas interdependentes que produzimos e que nos produz (Capra, 1996; Morin, 2002a, 2002b, 2003).

A sociedade nega os princípios dialógico e hologrâmico do pensamento complexo. Primeiro, quando exclui o "louco" em detrimento do "não-louco", e quando não considera o "louco" inscrito na sociedade, assim como a sociedade está inscrita no "louco".

Tomando outra dimensão da relação entre o sistema pequeno grupo Oficina de Capoeira e a organização Comitê de Ética, podemos dizer que a interlocução entre eles levou a pesquisadora a questionar-se sobre os sentidos da capoeira nessa oficina. Um movimento que produziu, a um só tempo, um voltar-se para si e para o sistema pequeno grupo, levando a pesquisadora à construção de uma pergunta: esta oficina produz um sentido próprio, único, singular e, ao mesmo tempo, múltiplo sobre a capoeira ali desenvolvida? Eis o princípio da reintrodução do conhecimento em todo conhecimento (Morin, 2002a, 2002b, 2003).

Após os questionamentos do Comitê, percebemos a necessidade de dialogar com os participantes da pesquisa sobre a capoeira desenvolvida naquela oficina. Durante alguns diálogos com o professor de Educação Física, ele lembrou do primeiro ano de funcionamento da oficina, da proposta de um ensino formal de capoeira, ou seja, da construção de encontros planejados, com aulas dirigidas. Lembrou-se também do período que tinha como uma das questões fundamentais para desenvolvimento da Oficina a presença de um Mestre de Capoeira, ou seja, a presença de um sujeito que representasse a formalidade da capoeira na atualidade, com suas regras, valores, crenças, cultura, etc., porém, algo que, nesse diálogo, nos chamou a atenção e que, no nosso entender constituiu-se como um grande diferencial, foi o fato de nós - pesquisadora e professor de Educação Física - nos colocarmos na oficina, ou seja, num lugar de escuta para vontades e necessidades. Acreditamos ter sido esse fato o que 
possibilitou a produção de um espaço livre para a espontaneidade, para a interlocução entre diferentes saberes. Escuta que emergiu como um organizador do pequeno grupo (Seminotti, 2004). Organizador que configurou as relações entre pesquisadora, professor de Educação Física e demais participantes da oficina. Foi a partir deste organizador grupal que a capoeira "tradicional" passou a dar lugar a uma capoeira lúdica. Esta, que, na convivência, na inter-relação, se constituiu como um modo de expressão dos sujeitos no grupo, configurando novas relações no sistema pequeno grupo que, por sua vez, determinaram as características e a identidade do sistema. Foi a capoeira que deixou de ser o fim de uma aprendizagem para tornar-se o meio pelo qual os sujeitos se produzem e constroem novos modos de existência. Foram os organizadores deste sistema pequeno grupo - escuta e capoeira - que potencializaram relações, interações, interlocuções, socializações entre diferentes sujeitos, entre moradores da vila, usuários do hospital, professor de Educação Física e pesquisadora, contribuindo para a auto-organização do sistema pequeno grupo.

A perspectiva de construir um caminho enquanto caminhávamos pela investigação (Morin, 2002a) possibilitou-nos dialogar com outros participantes da Oficina de Capoeira. Assim, em o7 de agosto de 2004, cinco meses após termos respondido ao Comitê de Ética sobre a capoeira desenvolvida na oficina, as crianças, sujeitos deste sistema pequeno grupo, expressaram verbalmente um modo de compreender/viver a capoeira.

(...) Maria (usuária da unidade de internação feminina) começa a fazer algumas perguntas para mim sobre as crianças (de onde são?, onde moram?, estão internadas no São Pedro?). Digo que ela pode fazê-lo diretamente para as crianças. Então, pergunta:

- O que vocês fazem aqui? A capoeira é bom para quê? O que vocês sentem fazendo capoeira? O pai e a mãe incentivam vocês a virem aqui?

Dentre as respostas para os questionamentos de Maria, as crianças disseram:

- Capoeira é bom pra saúde.

- Capoeira é bom pra se defender.

- Eu venho porque eu gosto.

- Capoeira é brincadeira!

A resposta que imediatamente fez sentido, para mim, ao ouvir as crianças, foi quando Beatriz diz rapida- mente: "Capoeira é brincadeira", sem se preocupar em formular uma resposta "correta". Neste momento, compreendo que alguns fios da rede de relações que se produziu neste sistema pequeno grupo foram tecidos. Aquelas crianças se produziram na brincadeira, no lúdico da capoeira.

Digo isto porque em meio aos questionamentos de Maria, também fiz outros questionamentos complementares aos dela, buscando resgatar a história da capoeira, sua relação com os negros escravos, sua conceituação enquanto esporte, dança, jogo, luta, e ao tecer este comentário, Beatriz, sem questionamentos, traz a palavra brincadeira. Complementação de Beatriz, que, na minha compreensão, foi acolhida por outras crianças que silenciaram após a fala da menina, pararam para refletir sobre o emergente.

Aproveitei este momento para perguntar também às usuárias e [aos] usuários do hospital, o porquê estavam ali, numa oficina de capoeira. As respostas foram as seguintes:

- Curiosidade.

- Queria conhecer.

- Queria conhecer as moças (referindo-se às meninas da vila), pois Michele já tinha falado delas pra nós.

$\varepsilon$ Michele complementa:

- É, eu já tinha falado das crianças e da capoeira. Eu até perguntei pro Vitor se ia ter capoeira hoje.

(Fragmento do diário de campo, escrito em 07/o8/ 2004).

O fragmento acima descrito sugere a emergência do sentido lúdico da capoeira nesse sistema pequeno grupo em meio a outros dois sentidos - manutenção da saúde e defesa pessoal - que, do nosso ponto de vista, remetem ao contexto maior de nossa sociedade, ou seja, sentidos produzidos pelo sistema maior onde a Oficina de Capoeira está inserida e que, conforme o princípio hologrâmico (Morin, 2002a, 2002b, 2003), mostraram-se inscritos neste sistema pequeno grupo.

Em diálogo com as informações do diário de campo ficam evidentes algumas situações que expressam a tranversalização da ludicidade da capoeira junto aos usuários e trabalhadores do hospital quando, por exemplo, os usuários das unidades de internação masculina chamavam a atenção das crianças dizendo: "a capoeira não é para brigar, mas sim para brincar"; quando estes mesmos sujeitos, ao retornarem para suas unidades, após a realização da oficina, chegavam 
dizendo aos demais internos: "vocês não sabem o que perderam... a melhor coisa que acontece neste hospital"; quando um trabalhador em saúde desta mesma unidade de internação masculina verbaliza: “se é para ir lá jogar, brincar eu também quero"; quando um dos coordenadores do hospital solicitou ao professor de Educação Física a realização de uma Oficina de Capoeira para os trabalhadores em saúde do hospital.

Um sentido lúdico da capoeira, portanto, que foi produzido nas ações, interações e recursões entre pesquisadora, professor de Educação Física, crianças moradoras da vila e usuários e trabalhadores do hospital. Eis o princípio sistêmico e o princípio do circuito recursivo propostos por Morin (2002a, 2002b, 2003).

Princípios que também são evidenciados quando refletimos sobre as mudanças que a pesquisadora e a própria Oficina de Capoeira vivenciaram a partir do questionamento levantado pelo Comitê de Ética. Ou seja, questionamento que fez a pesquisadora voltar o seu olhar de modo mais intenso para a capoeira produzida neste sistema pequeno grupo. E, por conseqüência, desencadeou na própria oficina uma importante discussão sobre os sentidos da capoeira ali expressos e vividos. Pesquisadora que produziu o sistema pequeno grupo ao mesmo tempo em que por ele foi produzida.

\section{A Rede de Relações entre a Vila São Pedro e a Ofi- cina de Capoeira}

As crianças participantes da Oficina e moradoras da vila constituíram-se sujeitos importantes para a construção de uma rede de relações entre a pesquisadora e a comunidade da Vila São Pedro como um todo, formando relações de entrelaçamento e interdependência, como nos sugere Capra (1996) e Morin (2002a, 2002b, 2003).

Inicialmente, nem a pesquisadora nem o professor de Educação Física sentiam-se autorizados a transitar pelos becos e ruelas da vila. Caminhavam apenas pela sua única rua principal que permite acesso a carros e caminhões. Somente quando uma das crianças os convidou para entrar em um beco que dá acesso à casa de duas meninas participantes da Oficina foi que eles passamos a transitar pelos becos da vila. Esse acontecimento foi possível após um ano de inter-retroações com a comunidade. Foram as crianças, sujeitos, que abriram caminhos concretos na vila e, ao mesmo tem- po, abriram caminhos para a produção de relações humanas, ou seja, caminhos para a construção de uma rede de relações onde o lugar e os sujeitos estão presentes. Essa abertura remete a sistemas abertos ao fluxo de energia e informação do meio ao qual pertencem (Morin, 2002a, 2002b, 2003; Prigogine, 1999).

Segundo e professor de Educação Física, ainda no primeiro ano de realização do sistema pequeno grupo Oficina de Capoeira, os garotos que vendiam drogas na vila tratavam-no como cliente, ou seja, ofereciam a ele as substâncias e/ou indicavam os caminhos onde elas podiam ser adquiridas. Na convivência com esses garotos, essa relação foi se modificando, até que eles passaram a identificá-lo como o professor de capoeira. Foram vários os momentos em que esses garotos deram orientações sobre onde estariam algumas das crianças participantes da Oficina ou, até mesmo, se comprometeram em chamá-las. Alguns deles chegaram a se aproximar da pesquisadora manifestando o interesse em participar da Oficina de Capoeira.

A relação humana construída expressa comprometimento e respeito recíproco, possibilitando o convívio de inegáveis diferenças que se abrem entre a pesquisadora e o professor de Educação Física em relação aos garotos que vivem do tráfico de drogas. Tomando os princípios hologrâmico, sistêmico, recursivo e dialógico (Morin, 2002b, 2003), podemos dizer que a configuração desta relação humana possibilitou a aproximação, o contato, a troca, a inter-relação entre a comunidade da Vila São Pedro e a Oficina de Capoeira. Se inicialmente a comunidade se relacionava com a pesquisadora e com professor de educação física, posteriormente esta relação se estendeu para a Oficina de Capoeira como um todo.

A roda de capoeira realizada na área central da vila remete às relações construídas entre a Oficina e a comunidade. Em diálogo com o professor de Educação Física, lembramos que inicialmente a proposta era que a roda fosse realizada em meio aos Serviços Residenciais Terapêuticos. Espaço que, naquele momento, era mais familiar, conhecido e seguro para todos, porém, a interação entre as crianças participantes da Oficina produziu efeitos sobre seus familiares que, a partir de um conjunto de interações, criaram uma outra possibilidade para a realização da roda. Essa criação retroagiu sobre o sistema pequeno grupo fazendo com que a roda de capoeira acontecesse na rua principal 
da Vila São Pedro, em uma localização central, parando todo o trânsito de carros, caminhões, carroças e transeuntes.

Considerando a retroação da criação dos sujeitos sobre o sistema pequeno grupo, pode-se dizer que o todo desse sistema passou a ser mais do que seu próprio todo (Morin, 2002b). É possível lembrar de algumas falas de sujeitos anônimos naquele contexto, mas que ajudaram a produzir esse acontecimento: "Agora não pode passar, as crianças estão se apresentando!”, "Deixa o caminhão ai esperando, não dá para passar, é a capoeira”.

A roda de capoeira acabou por se tornar um acontecimento singular no contexto desta comunidade (Morin, 2002b) e que muito contribuiu para a configuração de uma rede de relações humanas que expressa respeito e comprometimento mútuo, produzida na interconexão, no entrelaçamento, na interdependência entre diferentes sujeitos, sistemas vivos e sociais (Capra,1996; Morin, 2002a, 2002b) e que culminou em um objetivo comum: a Oficina de Capoeira.

\section{As Mudanças nas Relações entre Sujeitos e Siste- ma Pequeno Grupo}

Na convivência com o estranho, com o "louco", as crianças participantes da Oficina subjetivaram-se produzindo outros modos de ver, sentir, perceber este outro e a si próprios. Produzindo, sobretudo, autonomia para a construção de novas relações e idéias, novos modos de agir e pensar sobre o outro e sobre si.

No caminho para o São Pedro, Tamara pergunta se Marina (usuária da unidade de internação feminina) irá participar da Oficina e, em seguida, comenta com Andréia:

- Vamos brincar de pegar com a Marina? A Marina vai ir, Sora?

(...) Em meio a estes jogos e brincadeiras, Tamara voltava a falar em Marina, dizendo que gostaria de ter com ela brincado e Lucas lembrava de Antônia (usuária da unidade de internação feminina) tentando reproduzir no pandeiro o toque que ela havia lhe ensinado. (Fragmento do diário de campo, 26/o6/o4).

(...) No caminho para o hospital, Tamara pergunta novamente se Marina irá participar da Oficina. Respondo dizendo que não sabia, mas que provavelmente ela já não estaria mais no hospital, que já teria recebido alta. Tamara ficou brava e disse que se Marina não participasse mais, ela também não participaria. Então, outra criança pergunta sobre Antônia (...). As crianças não gostaram de saber que nem Marina, nem Antônia viriam à Oficina e passaram a questionar sobre por quê elas não poderiam vir de suas casas, já que não estavam mais no hospital.

(...) Ao final da Oficina, ouvimos o seguinte comentário por parte de algumas crianças:

- A Marina não veio mas a gente fez outras amigas.

(Fragmento do diário de campo, o3/o7/o4).

- Sora, eu to com saudade... até sonhei com aquela que canta! (...) Tamara acrescenta:

- É Sora, a Marina tinha que vim visitar a gente. Se a Marina não vai eu também não vou na capoeira. (Fragmento do diário de campo, 10/o7/o4).

As crianças buscaram nas brincadeiras de pegar, no toque do pandeiro, no jogo de capoeira, na expressão corporal, como um todo, segurança para o estabelecimento de interações com o diferente, que por sua vez, produziram mudanças individuais e coletivas. A convivência com o "louco" e o conhecimento sobre as diferentes facetas que constituem este "louco" possibilitaram a produção de pequenas aberturas nos sistemas das idéias que as crianças participantes do pequeno grupo Oficina de Capoeira produziam e que, recursivamente, possibilitaram maior aproximação dos usuários do hospital junto à Oficina de Capoeira. (..) quando estávamos caminhando pela vila em direção ao hospital, fui abordada pelo Mário, ex-usuário da unidade de internação masculina, que no ano passado participou da Oficina de capoeira (...). Ao me ver, Mário diz:

- Oi, já estão indo para a capoeira?

- Posso ir mesmo? Hoje eu to aqui de bobeira e ele (aponta para um menino morador da vila e participante da Oficina) já tinha me convidado!

(...) Chegando no hospital, as crianças começam a brincar no gramado próximo ao portão que divide a vila do hospital. Mário chega e é cumprimentado por um dos vigilantes do hospital, este pergunta se ele irá fazer capoeira, Mário responde dizendo que sim, que irá passar alguns dos seus conhecimentos de capoeira para as crianças. Então ele começa a interagir (...).

(...) Ouvia a voz do Mário ao longe cantando, o professor de Educação Física tocando pandeiro e todos os demais cantando e batendo palmas. (...) Via as crianças jogando entre elas e com alguns usuários, via os 
usuários convidando uns aos outros para jogarem, via diferentes interações, múltiplas relações sendo construídas.

\section{(...) Antes de encerrar a Oficina (...) Mário diz:}

- Eu queria dizer que já faz um tempo que eu quero vir aqui fazer capoeira... eles já haviam me convidado mas por uma coisa ou outra eu não pude, mas hoje eles estavam passando eu estava sem fazer nada e vim aqui... gostei de estar com a criançada.

(Fragmento do diário de campo, 17/o7/o4).

Essas aberturas subjetivaram cada sujeito e possibilitaram que as crianças transitassem entre conceitos socialmente construídos sobre o "louco": aquele que pega, agride, mata, e conceitos que no próprio sistema pequeno grupo acabou sendo produzido: não é "louco", é doente. Sistema vivo, portanto, aberto e fechado a um só tempo (Morin, 2002b, 2003).

Estávamos caminhando no espaço do São Pedro, em direção ao Gigantinho, quando Milene, uma nova participante da Oficina, diz:

- O Sor tá com medo dos louquinho.

Vanessa então intervém dizendo:

- Não é louquinho Milene, édeficiente, édoente!... (Fragmento do diário de campo, 01/05/o4).

Ao chegar na casa do Lucas e da Tamara, algumas crianças da comunidade que não participavam da Oficina começam a conversar comigo dizendo:

- Hoje vai ter capoeira Sora?

- Onde vai ser? No São Pedro?

- Ha-ha-ha, lá eu tenho medo dos "louquinho"!

Então Débora se aproxima e diz:

- Não é louquinho, é doente! Eu não tenho medo, eles são doente. (...) No início eu tinha medo Sora, mais aí eu vi que eles são doente. (Fragmento do diário de campo, 22/05/o4).

O conceito "não é louquinho, é doente" nos intrigou, quanto a sua construção da expressão. Em muitos diálogo sobre as informações produzidas na investigação, questionamos o quanto estávamos contribuindo para a construção desta expressão. Tomando-se a perspectiva da integração entre observador e observação (Morin, 2002b, 2003), torna-se evidente a contribuição tanto da pesquisadora, quanto do professor de Educação Física na construção desse conceito. Todavia, outros sujeitos e outros sistemas também influenciaram para que as crianças participantes da Oficina passassem a referir-se aos usuários do Hospital
São Pedro como doentes. Nesse sentido, outros fios desta rede de relações começaram a ser tecidos.

(...) Ao chegar na vila, um menino de aproximadamente cinco anos de idade diz:

- Inscreve eu, Sora. Eu quero fazer capoeira.

Então pergunto...

- Mas tu não tem medo de ir no São Pedro?

Então ele responde com outra pergunta...

- Medo dos louquinhos? Eu não, eu não tenho medo deles.

É interessante notar que eu não perguntei se ele tinha medo dos "louquinho" mas sim de entrar no São Pedro, e rapidamente ele, menino de 5 anos, identificou o "não dito" de minha pergunta.

A avó da Renata que estava acompanhando a conversa fez uma intervenção dizendo:

- Não são louquinhos, são doentes. Eu ensino minha netinha que tem a mesma idade dele que não é louquinho que é doente, que eles estão se tratando. (Fragmento do diário de campo, 26/o6/o4).

No momento em que a avó de Renata expressou o modo como ensina sua neta mais nova a se referir aos usuários do Hospital São Pedro, ficou evidente para nós a importância do sistema familiar para a produção do conceito "não é louquinho, é doente". Em diálogo com o professor de Educação Física, lembramos das inúmeras vezes que Vanessa, participante da Oficina, repetiu a seguinte frase: "Em casa, a minha mãe me diz que não é louquinho, é doente. Ela sabe, ela já trabalhou no São Pedro". Eis o claro atravessamento do processo de reforma psiquiátrica vivido pelo hospital sobre a comunidade da vila. A mãe de Vanessa foi trabalhar no Hospital São Pedro, quando da proposta de abertura das portas do hospital à comunidade através de vários projetos, como, por exemplo, o projeto de Geração de Renda, aberto tanto para moradores da vila, quanto para funcionários do hospital.

Este modo de compreender o "louco" possibilitou inúmeras aproximações, interações, socializações e recursões, possibilitando a configuração de novas relações entre as crianças da vila e os usuários do hospital. A expressão "não é louquinho, é doente" acabou por emergir como mais um organizador (Seminotti, 2004) do pequeno grupo Oficina de Capoeira, potencializando interações entre diferentes sujeitos e sujeitos diferentes.

Não obstante, mesmo sendo a expressão "não é louquinho, é doente" uma produção do grupo, atraves- 
sada por outros diferentes sistemas, ainda se fala de alguém distante, estranho: se não é louco, é doente. "Doença esta que está no outro e longe de mim". 0 outro (diferente) causa curiosidade e inquietações nessas crianças, que para conhecê-lo, se separam deles a partir da diferença encontrada na doença e se aproximam deles a partir da semelhança encontrada na humanidade.

Débora (...) pergunta sobre a participação dos usuários do hospital na Oficina, porém diz que se eles participarem ela não participará. (...) Vanessa diz:

- Eu não tenho medo deles, eles são que nem a gente, só que eles são doentes. (Fragmento do diário de campo, 03/07/04).

No percurso em direção ao São Pedro algumas das crianças perguntaram (...):

- Quando é que aqueles outros vão participar da capoeira (referindo-se aos usuários e usuárias das unidades de internação masculina e feminina). (Fragmento do diário de campo escrito em o8/05/04).

Ao chegarmos no São Pedro, (...) Vanessa faz o seguinte questionamento:

- O Sora, os coisa não vão vim?

- Que coisa? (pergunto).

- Vanessa: Aqueles aqui do São Pedro. (Fragmento do diário de campo, 05/06/04).

As expressões "aqueles outros”, “os outros”, “os coisa" e "aqueles" remetem ao desconhecido, ao alheio, ao estranho. As crianças participantes da Oficina de Capoeira produziram pequenas aberturas, mas não o rompimento com o modo de pensar o "louco". As aberturas não garantem que essas crianças não tenham medo de um "louco" qualquer, mas possibilitam a aproximação, a interação com o outro "louco", que não é conhecido. Todavia, será na convivência com esse "louco" que as crianças poderão se abrir e se fechar a essas novas relações. O medo do "louco", em muitas situações, pode ser desconstruído na interretroação entre sujeitos, pequeno grupo e sistema maior. Todavia, isto não significou a abertura total do sistema que lhes era estranho, alheio, desconhecido; ao contrário, sinalizou pontos que não podem ser abertos neste contexto histórico-social.

Por mais que a interação tenha potencializado o convívio entre diferentes - "loucos e não-loucos" -, ela não garantiu a tolerância a outras diferenças que se tornaram evidentes no sistema pequeno grupo.
Vanessa e Andréia foram porta-vozes desta relação. Dentre os novos participantes da Oficina, neste dia, realizamos a inscrição da tia de duas meninas que já haviam participado da Oficina em anos anteriores. Esta nova participante, Silvia, é deficiente física (muda e deambula com certa dificuldade) e no ano anterior já havia mostrado interesse em participar da Oficina. Quando, ainda no ano passado, dissemos que se sua mãe autorizasse ela poderia participar, Vanessa questionou dizendo que ela não sabia fazer capoeira, e dizia:

- "Não inscreve ela, sora! Ela não sabe!". (Fragmento do diário de campo, 28/o4/o4).

(...) Uma menina, Andréia, que já havia participado da Oficina, solicita que eu a acompanhe até a casa dela para falar com sua mãe. Eu me dirijo até a casa de Andréia. (...) A irmã de Andréia também solicita participar da Oficina e sua mãe diz:

- “Não, tu não sabe, é difícil!", e Andréia reafirma o comentário da mãe dizendo,

- "É tu não sabe capoeira"

(...) A mãe das meninas autoriza a participação de ambas. Cabe salientar que esta menina, irmã de Andréia, aparenta ter algum tipo de retardo mental. Saímos (...) e Andréia continua,

- "Diz para ela ir embora, Sora, não inscreve ela, não deixa ela ir, Sora, ela não sabe capoeira"

Esta atitude de Andréia e de sua mãe me fizeram lembrar de quando realizamos a inscrição de Sílvia, ou seja, de que Vanessa havia agido de modo parecido quando convidamos Sílvia a participar da Oficina (...). (Fragmento do diário de campo, 30/o4/o4).

Os fragmentos acima transcritos falam sobre a multiplicidade e a diversidade que constituíram a Oficina de Capoeira. Unidade múltipla que se mostrou aberta para algumas diferenças, mas fechada para outras. O sistema pequeno grupo que se desorganizou diante da diferença que lhe era estranha, alheia, que inibiu relações, articulações no sistema pequeno grupo, tornando-o, neste momento, menos do que a soma das partes (Morin, 2002b). Ao identificar esse momento do sistema pequeno grupo, o professor de Educação Física fez algumas intervenções, proporcionando novas informações que retroagiram sobre o sistema, produzindo novas relações e uma nova organização: um sistema pequeno grupo com potencial de se autoecoorganizar (Morin, 1996, 2002b, 2003). 


\section{A Rede de Relações entre os Serviços Residenciais Terapêuticos, a Vila São Pedro e a Oficina de Ca- poeira}

A Oficina de Capoeira também possibilitou certa abertura da organização Serviços Residenciais Terapêuticos para aquela que constitui a Vila São Pedro e viceversa, ou seja, as relações entre moradores da vila e dos residenciais terapêuticos puderam ser estreitadas. Isso pode ser observado de acordo com os relatos de trabalhadores do hospital que, ao realizarem uma festa junina no espaço dos Serviços Residenciais Terapêuticos, observaram uma importante movimentação de um grupo de crianças da comunidade da Vila São Pedro. Esses trabalhadores relataram ao professor de Educação Física que o grupo de crianças se aproximou do local onde a festa estava sendo realizada e, espontaneamente, começou a interagir com os trabalhadores e moradores dos residenciais terapêuticos. 0 professor de Educação Física contou à pesquisadora que, para a surpresa de todos, os trabalhadores descobriram que aquelas crianças participavam da Oficina de Capoeira. Esse acontecimento reafirma as aberturas possíveis vividas por estas crianças e que lhes possibilitou a produção de outros modos de ver, sentir, tocar, comunicar com o outro, com o "louco". Um acontecimento concreto e singular que demonstrou um processo de mudança desencadeado em cada uma daquelas crianças, e quem sabe, nos moradores dos Serviços Residenciais Terapêuticos e da Vila São Pedro.

Não obstante, na produção dessa rede de relações entre esses diferentes sistemas também ficam evidentes as relações de tensão e conflito entre moradores da Vila São Pedro, dos Serviços Residenciais Terapêuticos e do Hospital São Pedro.

Chegamos no hospital e fomos em direção ao gramado (...). No caminho encontramos Otacílio, morador do São Pedro que cuida dos cachorros que habitam o hospital. Ao nos aproximarmos, seus cachorros começam a latir deixando as crianças assustadas. Otacílio levanta-se de onde estava sentado, acalma seus cachorros e nos dá passagem. Pablo, ao ver Otacílio diz que tem medo dele, que ele e outros meninos da vila lhe apelidaram de Hulk. Diz que tem medo porque outro dia a chamar Otacílio de Hulk, este saiu correndo atrás dele e dos outros meninos. (Fragmento do diário de campo, 26/o6/o4).
A situação acima descrita não foi a única que as crianças relataram sobre apelidos dados a alguns moradores do hospital e dos residenciais terapêuticos. Todavia, algo que nos chamou a atenção foi de esses apelidos serem criados e utilizados quando as crianças participantes da Oficina de Capoeira formavam outros grupos, com outras crianças da comunidade. Nesse sentido, percebemos a existência do que chamamos de "código de ética", presente fundamentalmente no espaço da Oficina, configurando um outro tipo de relação produzida no sistema pequeno grupo. Entendemos que esse "código de ética" emergiu como mais um organizador do sistema pequeno grupo (Seminotti, 2004). Quando algumas das crianças estavam longe da Oficina, constituindo outros grupos, percebemos que elas se permitiam o rompimento desse código. A organização remete, portanto, ao sistema pequeno grupo Oficina de Capoeira e ao contexto no qual está inserido, o contexto da reforma psiquiátrica.

\section{Considerações Finais}

Houve cooperação mútua no avanço da produção e da organização do sistema pequeno grupo Oficina de Capoeira, na configuração de sua rede de relações: as crianças que abriram caminhos enquanto a pesquisadora e o professor de Educação Física caminhavam pela comunidade da Vila São Pedro; os familiares dessas crianças que abriram as portas de suas casas, que se abriram para o diálogo e para a interação com o desconhecido; a comunidade como um todo que nos deu acesso à parte de sua intimidade; os usuários do Hospital São Pedro que abriram caminhos no hospital para a entrada das crianças da comunidade da vila; os trabalhadores do hospital que abriram caminhos para a Oficina de Capoeira; o professor de Educação Física e a pesquisadora que se abriram para juntos caminharem pelos diferentes caminhos que poderiam surgir.

Uma relação onde uns dependem dos outros para se tornarem mais autônomos. A pesquisadora, participante do sistema pequeno grupo, ao desconstruir seus castelos de saberes, passou a valorizar a minúcia, o detalhe, o óbvio, produzido nas inter-relações, articulações, recursões, socializações entre sujeitos e realidades tão distintas e distantes e, ao mesmo tempo, tão semelhantes e próximas, quando tomadas sob a dimensão da exclusão social. Um modo de conhecer 
que se dá na relação, um caminho que resolvemos percorrer para nos deixar dependentes do saber do outro, mas que também nos possibilita a autonomia para a construção deste e de outros caminhos. Crianças e familiares da vila e usuários do hospital que passaram a conhecer com maior propriedade as facetas de uma realidade que mora ao lado, próxima e ao mesmo tempo distante, separada apenas por um muro de tijolos, mas que diz muito sobre uma importante construção social que separa, desarticula as noções de loucura e normalidade.

Na convivência, crianças da vila, usuários do hospital, professor de Educação Física e pesquisadora subjetivam-se, produzindo outros modos de ver, sentir, perceber uns aos outro e a si próprios, produzindo autonomia para a construção de novas relações e idéias, outros modos de agir e pensar sobre o outro e sobre a si próprio.

A contextualização do sistema pequeno grupo Oficina de Capoeira no movimento de reforma psiquiátrica produziu efeitos sobre outros sistemas, como, por exemplo, no sistema familiar cujas crianças participantes da Oficina estão inseridas, gerando reflexões e questionamentos que retornaram ao sistema pequeno grupo num movimento recursivo, gerando novas informações e subjetivando cada sujeito. Essa contextualização possibilitou ao sistema pequeno grupo produzir-se a partir da diversidade de seus participantes, potencializando interações, socializações, articulações entre sujeitos, entre os ditos "loucos" e “não-loucos”. Essa contextualização está intrinsecamente relacionada à emergência dos organizadores grupais, que muito contribuíram para a organização do sistema pequeno grupo Oficina de Capoeira.

Na perspectiva do pensamento complexo, sujeito, pequeno grupo e contexto maior são constitutivos uns dos outros, a um só tempo, produzindo-se mutuamente, pois cada um se abre ao outro. Esta interferência recíproca caracteriza uma relação dialógica, sistêmica, hologrâmica, complexa, onde sujeito, pequeno grupo e sociedade constroem aberturas para além dos próprios limites da compreensão humana, em que nos deparamos com a incompletude, com a instabilidade, com a incerteza, com o caos, com o complexo. Acreditamos que os acontecimentos, as organizações e desorganizações, as subjetivações e as sujeições vividas por todos aqueles que foram interpelados pelo siste- ma pequeno grupo Oficina de Capoeira ultrapassam seus limites, suas fronteiras individuais, atravessando, portanto, outros sistemas, outros contextos, produzindo recursivamente mudanças na realidade cotidiana de diferentes vidas, diferentes existências, diferentes sistemas pequenos grupos.

O sistema pequeno grupo Oficina de Capoeira nos sugere outras possibilidades de ação, de intervenção, de trabalho com pequenos grupos no contexto da reforma psiquiátrica, todavia, precisamos viver a aleatoriedade, a heterogeneidade, a incerteza, a instabilidade do sistema como possibilidade de produção de sujeitos criativos, escapando, assim, das universalizações e classificações a qual somos constantemente submetidos: "loucos" e "não-loucos". Precisamos estar abertos ao desconhecido, tal como os participantes da Oficina de Capoeira. Essa abertura pressupõe o fechamento para a manutenção da singularidade, da identidade do sistema vivo.

\section{Referências}

ALVES, M.; MALAVOLTA, M. de A. Desconstruindo o manicômio mental no cotidiano da comunidade da Vila São Pedro. In: FERLA, A.; FAGUNDES, S. (Org.). O fazer em saúde coletiva: inovações da atenção à saúde no Rio Grande do Sul. Porto Alegre: Da Casa: Escola de Saúde Pública/RS, 2002. p. 157-177.

ALVES, M.; SEMINOTTI, N. Produção e organização do Sistema Pequeno Grupo "Oficina de Capoeira": um estudo no contexto da reforma psiquiátrica. 2005. Dissertação (Mestrado em Psicologia) - Faculdade de Psicologia da Pontifícia Universidade Católica do Rio Grande do Sul, Porto Alegre, 2005.

AMARANTE, P. Algumas reflexões sobre ética, cidadania e desinstitucionalização na reforma psiquiátrica. Saúde em Debate, Londrina, n. 45, p. 43-46, dez. 1994.

BAREMBLITT, G. Por una nueva clinica para el poliverso "PSY". In: LANCETTI, A. (Org.). Saúdeloucura: a clínica como ela é. São Paulo: Hucitec, 1997. p. 11-30.

BRASIL. Ministério da Saúde. Conselho Nacional de Saúde. Resolução nº 196, de 10 de Outubro de 1996. Diretrizes e normas regulamentadoras de pesquisas envolvendo seres humanos. Disponível em: <http:// portal.saude.gov.br/portal/arquivos/pdf/anexo_3.pdf $>$.

Acesso em: 11 janeiro 2006. 
CAMBRAIA, M. As práticas e os processos de trabalho nos ambulatórios de saúde mental. 1999. Dissertação (Mestrado em Saúde Pública) - Faculdade de Saúde Pública da Universidade de São Paulo, São Paulo, 1999. CAPRA, F. A teia da vida. São Paulo: Cultrix, 1996. CONSELHO FEDERAL DE PSICOLOGIA. Resolução no o16, de 20 de Dezembro de 2000 . Dispõe sobre a realização de pesquisa em Psicologia com seres humanos. Brasília, DF, 2000.

DELEUZE, G. Crítica e clínica. São Paulo: Ed. 34, 1997. GOLDBERG, J. Clínica da psicose: um projeto na rede pública. 2. ed. Rio de janeiro: Te Corá: Instituto Franco Basaglia, 1996.

GUATTARI, F. Caosmose: um novo paradigma estético. Rio de Janeiro: Ed. 34, 1992.

KINOSHITA, R. T. O outro da reforma: contribuições da teoria da autopoiese para a problemática da cronicidade no contexto das reformas psiquiátricas. 200o. Tese (Doutorado em Saúde Coletiva) - Universidade Estadual de Campinas, São Paulo, 2000.

LANCETTI, A. A clínica como ela era. In: LANCETTI, A. (Org.). Saúdeloucura: a clínica como ela é. São Paulo: Hucitec, 1997. p. 181-192.

MACEDO, A. L. P.; MARON, M. da G. R. A clínica e a reforma psiquiátrica: um novo paradigma? Jornal Brasileiro de Psiquiatria, Rio de Janeiro, v. 46, n. 4, p. 205211, abr. 1997.

MORIN, E. A noção de sujeito. In: SCHNITMAN, D. F. (Org.). Novos paradigmas, cultura e subjetividade. Porto Alegre: Artes Médicas, 1996. p. 45-58.

MORIN, E. O método. Porto Alegre: Sulina, 2002a.

MORIN, E. Ciência com consciência. 6. ed. Rio de Janeiro: Bertrand Brasil, 2002b.

MORIN, E. A cabeça bem feita: repensar a reforma, reformar o pensamento. Rio de Janeiro: Bertrand Brasil, 2003.

PRIGOGINE, I. O fim da ciência? In: SCHNITMAN, D. F. (Org.). Novos paradigmas, cultura e subjetividade. Porto Alegre: Artes Médicas, 1996. p. 25-40.
PRIGOGINE, I. Criatividade da natureza, criatividade humana. In: CARVALHO, E. de A.; MENDONÇA, T. (Org.). Ensaios de complexidade 2. Porto Alegre: Sulina, 2003. p. 21-26.

PRIGOGINE, I.; KONDEPUDI, D. Termodinâmica: dos motores térmicos às estruturas dissipativas. Lisboa: Instituto Piaget, 1999.

ROSA, L. C. dos S. As diferentes abordagens das reformas psiquiátricas, suas repercussões no Brasil e no Piauí. RASPP - Revista da Associação de Saúde Pública do Piauí, Teresina, v. 1, n. 2, p.146-154, jul./dez. 1998.

SEMINOTTI, N. La organización y dinámica del grupo psicológico: la multiplicidad/diversidad de organizadores del grupo. 200o. Tese (Doutorado em Psicologia) - Universidad Antónoma de Madrid, Madrid, 2000.

SEMINOTTI, N.; BORGES, B. G.; CRUZ, J. L. O pequeno grupo como organizador do ambiente de aprendizagem. Psico USF, Bragança Paulista, v. 9, n. 2, p. 191-189, jul./dez, 2004.

TENÓRIO, F. A reforma psiquiátrica brasileira, da década de 1980 aos dias atuais: história e conceito. História, Ciências, Saúde - Manguinhos, Rio de Janeiro, v. 9, n. 1, p. 25-59, jan./abr. 2002.

VASCONCELLOS, M. J. E. de. Pensamento sistêmico: o novo paradigma da ciência. Campinas: Papirus, 2003. VILLAS-BÔAS VALERO, P. $\bar{\varepsilon}$ preciso levar o delírio à praça pública: sofrimento psíquico, artes plásticas e inclusão social. 2001. Dissertação (Mestrado em Psicologia) - Instituto de Psicologia da Universidade de São Paulo, São Paulo, 2001.

WETZEL, C.; ALMEIDA, M. C. P. de. A construção da diferença na assistência em saúde mental no município: a experiência de São Lourenço, RS. Saúde em Debate, Londrina, v. 25, n. 58, p. 77-87, maio/ago. 2001.

ZIEGELMANN, L. Sofrimento psíquico: grupo como dispositivo de potências autopoiéticas. 2002. Dissertação (Mestrado em Psicologia) - Pontifícia Universidade Católica do Rio Grande do Sul, Porto Alegre, 2002. 